\title{
Política de Ciência, Tecnologia e Inovação em Saúde (CT\&I/S): uma atualização para debate
}

\author{
Health Science, Technology and Innovation Policy (ST\&I/H): \\ an update for debate
}

Reinaldo Guimarães (https://orcid.org/0000-0002-0138-9594) ${ }^{1}$

Carlos Medicis Morel (https://orcid.org/0000-0003-2752-0009) ${ }^{2}$

Érika Aragão (https://orcid.org/0000-0002-4903-0556) ${ }^{3}$

Julia Paranhos (https://orcid.org/0000-0003-4425-7484) ${ }^{4}$

Marisa Palácios (https://orcid.org/0000-0001-6507-4199) ${ }^{1}$

Moisés Goldbaum (https://orcid.org/0000-0002-8049-7824) ${ }^{5}$

Paulo Gadelha (https://orcid.org/0000-0002-5433-049X) ${ }^{6}$

Simone Kropf (https://orcid.org/0000-0002-9005-7160) ${ }^{7}$

${ }^{1}$ Núcleo de Bioética e Ética Aplicada, Universidade Federal do Rio de Janeiro (UFRJ). R. Venceslau Brás 71, Campus Praia Vermelha, Botafogo. 22290-140 Rio de Janeiro RJ Brasil. reinaldo. guimaraes47@gmail.com

${ }^{2}$ Centro de

Desenvolvimento

Tecnológico em Saúde,

Fundação Oswaldo Cruz

(Fiocruz). Rio de Janeiro

RJ Brasil.

${ }^{3}$ Instituto de Saúde Coletiva,

Universidade Federal da

Bahia. Salvador BA Brasil.

${ }^{4}$ Instituto de Economia,

UFRJ. Rio de Janeiro RJ

Brasil.

${ }^{5}$ Departamento de Medicina Preventiva, Faculdade de

Medicina, Universidade de São Paulo. São Paulo SP

Brasil.

${ }^{6}$ Instituto de Comunicação

e Informação Científica

e Tecnológica em Saúde,

Fiocruz. Rio de Janeiro RJ

Brasil.

${ }^{7}$ Casa de Oswaldo Cruz.

Fiocruz. Rio de Janeiro RJ

Brasil.
Abstract The text presents an updated proposal for a Health Science, Technology and Innovation Policy in Brazil, following the huge political turmoil in the country since 2019 and the COVID-19 pandemic since 2020. The proposal is presented in five sections: Scientific Research; Productive Innovation; Health Technology Assessment and Incorporation; Intellectual Property in Health; New challenges posed by the Pandemic. The authors take part in the Advisory Committee in Science, Technology and Innovation of the Brazilian Association of Collective Health.

Key words Health science and technology policy, Innovation in health, Health Technologies assessment and incorporation, Intellectual property in health, COVID-19 Pandemic
Resumo O texto contém uma proposta atualizada de política de Ciência, Tecnologia e Inovação em Saúde no Brasil e a pertinência da atualização decorre do desastre nas atividades nesse terreno verificadas no país desde o início do atual governo federal em 2019, bem como dos desafios colocados pela emergência da pandemia COVID-19 desde 2020. Ele está organizado em cinco seções, a saber: Pesquisa em Saúde; Inovação Produtiva; Avaliação e Incorporação de Tecnologias em Saúde; Propriedade Intelectual em Saúde; Novos desafios colocados pela Pandemia. Os autores fazem parte do Comitê de Assessoramento em Ciência, Tecnologia e Inovação da Abrasco.

Palavras-chave Politica científica e tecnológica em saúde, Inovação em saúde, Avaliação e incorporação de tecnologias, Propriedade intelectual em saúde, Pandemia de COVID-19 


\section{Nota Explicativa}

Este texto foi preparado sob os auspícios do Comitê de Assessoramento em Ciência, Tecnologia e Inovação da Abrasco e é assinado pelos membros do comitê que contribuiram formalmente com ele. Teve como ponto de partida um documento anterior, preparado com base na contribuição da Abrasco e do Centro Brasileiro de Estudos de Saúde (CEBES) para o $8^{\circ}$ Simpósio Nacional de Ciência, Tecnologia e Assistência Farmacêutica, promovido em dezembro de 2018 pelo Conselho Nacional de Saúde. Alguns meses depois foi publicado na revista Ciência \& Saúde Coletiva sob o título de "Política de Ciência, Tecnologia e Inovação em Saúde" . O texto original foi escrito após a emergência da conjuntura de "Uma Ponte para o Futuro" (2016), documento que marcou o programa de governo de Michel Temer e que se expressou, entre outros aspectos, nas limitações que seriam impostas pela Emenda Constitucional 95 que congelou os gastos públicos por 20 anos. Entretanto, ainda não havia sido inaugurada a conjuntura Jair Bolsonaro, na qual a politica econômica de Temer foi radicalizada e a fragilização da democracia no país emergiu com força. Mais ainda, no final de 2019 houve a eclosão da pandemia causada pelo SARS-CoV-2 que impactou todas as dimensões da vida politica e social. Estes fatos impuseram essa revisão e atualização, que tem a finalidade de contribuir com o tema e abrir um debate sobre ele.

\section{Introdução}

A política de CT\&I/S proposta pela Abrasco tem como diretrizes gerais: (1) a pluralidade nas abordagens científicas; (2) a ênfase nas tecnologias sustentáveis bem como a compreensão dos limites das tecnologias e do acesso às mesmas; (3) a ênfase em atividades de pesquisa que incorporem o conceito de saúde como direito. Além dessas três diretrizes, essa política tem como norte valorizar a cooperação sul-sul e, no plano nacional, enfrentar as desigualdades regionais e defender a utilização de instrumentos de discriminação positiva no fazer científico e tecnológico. A crise ambiental global vem se tornando um item central nas agendas políticas nacionais e seu enfrentamento tem na Agenda dos Objetivos do Desenvolvimento Sustentável (ODS) lançada pela ONU a mais abrangente referência para o debate global sobre valores e projetos planetários futuros. A presença da saúde na agenda é relevante e as dimensões científica e tecnológica ocupam lugar central, tanto na compreensão de suas interações sociais, culturais e econômicas, quanto por seu papel determinante na consecução dos ODS. No delineamento de uma política de CT\&I/S essa dimensão deve ocupar lugar de destaque.

Finalmente, a Abrasco considera o diálogo e a troca de experiências com outras entidades nacionais e internacionais no campo científico e tecnológico essenciais ao desenvolvimento de sua política.

Uma política de CT\&I/S compõe-se, pelo menos, de quatro pilares: O Sistema Único de Saúde, a base produtiva de bens e serviços de saúde, a massa crítica/capacidade instalada de ciência, tecnologia e inovação em saúde e as várias instâncias reguladoras e articuladoras das atividades dos três componentes. Esses quatro pilares vêm sendo erodidos por decisões políticas equivocadas e as propostas aqui contidas objetivam contribuir para uma correção dessa rota de destruição, projetando um caminho de futuro. $\mathrm{O}$ texto está organizado em cinco seções, a saber: Pesquisa em saúde; Inovação produtiva; Propriedade intelectual; Avaliação e incorporação de tecnologias; Ensinamentos da pandemia relativamente à política de CT\&I/S.

A organização do texto tem como suporte teórico o rico repertório conceitual dos sistemas nacionais, regionais e setoriais de inovação, originalmente imaginados por Christopher Freeman e Bengt-Åke Lundvall principalmente na Science Policy Research Unit (SPRU) da Universidade de Sussex na segunda metade dos anos de 1980 e mais tarde espalhados por vários outros centros voltados à economia da tecnologia e da inovação, inclusive no Brasil. A essa base, acoplam-se criticamente as contribuições mais recentes oferecidas por Mariana Mazzucato a partir de 2011, que ressaltam o papel do Estado como empreendedor, mais do que apenas articulador dos componentes dos sistemas de inovação. No caso do sistema setorial de inovação em saúde brasileiro, a presença do Estado é centralmente ocupada pelo SUS, mas também por outros entes como agências de fomento, empresas industriais públicas e privadas e prestadores de serviços que não o SUS. Embora o foco da reflexão dos criadores do modelo dos sistemas de inovação, como o próprio nome sugere, seja a inovação produtiva oriunda das empresas, o documento abraça também o papel da oferta de conhecimento, vale dizer a pesquisa científica e tecnológica. 


\section{Pesquisa em Saúde}

O termo pesquisa em saúde conforme utilizado nesta seção compreende o esforço científico e tecnológico vinculado à saúde humana levado a cabo em instituições de ensino superior e institutos de pesquisa. Corresponde ao que a literatura especializada norte americana denomina de STEM (science, technology, engineering and mathematics), acrescida das ciências humanas e sociais. Nesse sentido, pesquisa em saúde é apenas um capítulo da política de CT\&I/S, cuja integridade exige a presença dos temas constantes nas demais seções deste documento e eventualmente ainda outros, não contemplados aqui.

A pesquisa científica e tecnológica em saúde no Brasil possui uma tradição que antecede em muito o SUS e que remonta à primeira metade do século XX com Manguinhos, os institutos paulistas (Adolfo Lutz, Pasteur, Butantã, Emílio Ribas), o Instituto Evandro Chagas em Belém (criado como Instituto de Patologia Experimental do Norte), a Fundação Rockefeller, a Fundação SESP, a Faculdade de Saúde Pública da USP, entre outras instituições. No entanto, entre idas e vindas, um passo relevante mais recente na estruturação de uma política de pesquisa em saúde foi dado com a realização, em 1994, da $1^{\text {a }}$ Conferência de Ciência e Tecnologia em Saúde convocada pelo Conselho Nacional de Saúde e organizada sob os auspícios dos Ministérios da Saúde, da Ciência e Tecnologia e da Educação. Dentre as suas resoluções, destacam-se a que afirmava que "a política de C\&T em saúde é um componente da política nacional de saúde", e a outra, de caráter institucional, que propunha a criação de uma secretaria de ciência e tecnologia no Ministério da Saúde. Esta ideia só foi se concretizar em 2003, quase dez anos depois. Em 2004 houve a 2a Conferência, também em Brasília e também convocada pelo CNS, que pela primeira vez propôs uma política explícita nesse campo, bem como uma agenda de prioridades de pesquisa.

Uma política de pesquisa em saúde deve abarcá-la em sua integridade. Nessa perspectiva, podem ser identificados três vetores que a delimitam:

- as transições saúde-doença (promoção, prevenção, cura, reabilitação), aí incluídos os mecanismos biológicos, clínicos, epidemiológicos e sociais, que as determinam;

- os sistemas e as políticas de saúde aqui incluídos os componentes que prestam serviços e as indústrias produtoras de medicamentos, vacinas, diagnósticos, equipamentos e materiais de Saúde;
- a intersetorialidade na saúde e as relações entre saúde e sociedade.

Deriva daí que o delineamento de uma política de pesquisa para a saúde na perspectiva desse documento deve abraçar todos esses componentes e dimensões presentes nos três eixos, o que demanda uma perspectiva transdisciplinar que articule os campos das ciências biomédicas, da pesquisa clínica e epidemiológica, das ciências humanas e sociais e do planejamento e gestão em saúde, sem quaisquer reducionismos.

Essa abordagem evita circunscrever os esforços da criação científica e tecnológica às necessidades operacionais imediatas dos gestores do SUS, a despeito da importância das mesmas. Se a pauta da pesquisa em saúde tal qual aqui sugerida é uma pauta ampliada, é ela que devemos abraçar, em particular num momento em que se observa em todo o mundo uma aproximação espacial e temporal entre os resultados de pesquisa e a solução de problemas de saúde. A aproximação espacial se refere à cada vez maior interpenetração de ambientes físicos de pesquisa científica e tecnológica com unidades de pesquisa/desenvolvimento em empresas e na gestão governamental. A aproximação temporal se refere à crescente valorização de ferramentas que visam uma rápida tradução de aquisições científicas e tecnológicas em inovações no mercado que no campo da pesquisa em saúde tem sido chamada de "pesquisa translacional".

E isso, portanto, remete à necessidade de uma sinergia na formulação da política e de suas ações com os órgãos gestores do SUS, que é responsável por cerca de 1/3 do mercado de brasileiro de medicamentos, de $90 \%$ do mercado de vacinas, de $50 \%$ do mercado de equipamentos de saúde e de $100 \%$ dos serviços de todos os tipos e graus de complexidade prestados a todos os brasileiros por mandato constitucional. Por outro lado, essa política deve dialogar com o conjunto da massa crítica em saúde humana que, no Brasil, é a que detém o maior número de programas, discentes e docentes na Pós-Graduação, bem como a maior quantidade de pesquisadores envolvidos com linhas de pesquisa, de acordo com os dados disponíveis na CAPES e no CNPq.

De acordo com o Diretório dos Grupos de Pesquisa do Brasil gerido pelo CNPq, em 2018 havia 31.345 linhas de pesquisa que continham a palavra-chave "saúde humana", sendo a maior parte delas pertencentes a grupos vinculados à grande área do conhecimento das ciências da saúde. Ainda segundo a mesma fonte, cerca de $30 \%$ desse total de linhas de pesquisa pertencem 
a grupos cuja grande área do conhecimento predominante em suas atividades não era a de ciências da saúde. Portanto, uma política de CT\&I/S, tal como aqui proposta, deve ter como objeto de suas reflexões, propostas e ações todo esse conjunto. Vale observar que ano de 2018 muito provavelmente não reflete a situação atual do esforço científico e tecnológico brasileiro na esfera federal. Sua utilização aqui decorre da paralização da publicação (e, possivelmente da coleta) de informações estruturadas sobre esse esforço desde aquele ano. Isso é revelado pela consulta ao sítio do MCTI, onde as despesas nacionais com ciência, tecnologia e inovação desaparecem a partir de 2018-2019, pela precariedade das informações atualmente disponibilizadas pela Plataforma Sucupira da Capes e pelo desastre ocorrido em 2021 na gestão dos sistemas do CNPq. O acompanhamento e a avaliação da política brasileira de Ciência, Tecnologia e Inovação dependerá da reconstrução dessas fontes de dados e de seus canais de divulgação. Publicação mais recente atualiza as informações até 2020 e confirma essa paralisia na publicação dos dados sobre o esforço científico e tecnológico no Brasil2.

Desde 2000, o Departamento de Ciência e Tecnologia (DECIT) e outros componentes do Ministério da Saúde vêm prestando bons serviços ao desenvolvimento da pesquisa em saúde. Nessa trajetória destacam-se as parcerias de cogestão - inclusive de cofinanciamento - de programas e projetos realizados com as agências de fomento e outros componentes organizacionais já existentes no MS, MCTI e MEC, no CONFAP e no CONSECTI.

Vinculados ao Ministério da Saúde, embora detentores de grande autonomia operacional, destaca-se na pesquisa em saúde no Brasil o papel da Fiocruz e, num escopo temático mais restrito, do Instituto Evandro Chagas. Diferentemente de outras instituições que realizam pesquisa neste campo, elas são orientadas por missão, como convém aos institutos de pesquisa, e essa missão é servir ao SUS. Ainda nessa descrição de instituições com atividade de pesquisa em saúde, deve ser mencionado o conjunto de institutos vinculados a governos das unidades da federação, com destaque aos de São Paulo que têm larga tradição.

Entretanto, a maior parte da atividade de pesquisa em saúde no país, quando medida pela publicação em revistas especializadas e livros publicados, tem origem em universidades, faculdades e institutos de ensino e pesquisa não vinculados diretamente aos SUS, e são oriundos majoritariamente de seus programas de pós-graduação.
A política de CT\&I/S deve abraçar a totalidade das instituições que contribui com o avanço do conhecimento científico e tecnológico em saúde.

Em um programa de recuperação de nossa capacidade científica e tecnológica em saúde, deveriam ser valorizadas as formas organizacionais de trabalho capazes de multiplicar a energia presente na massa crítica mais capacitada e, ao mesmo tempo, contribuir para a descentralização geográfica da pesquisa brasileira. Nessa linha, destaca-se a modalidade do trabalho de pesquisas em rede onde se destaca o bem sucedido programa dos Institutos Nacionais de Ciência e Tecnologia (INCTs), que deveria ser ampliado e fortalecido. Vale notar que nesse programa, o campo de pesquisa em saúde é o mais bem representado dentre todos, com cerca de 1/3 das 101 redes apoiadas na primeira chamada de 2008.

Será também muito recomendável a retomada do ações governamentais voltadas à internacionalização da pesquisa brasileira, interrompidas desde 2017. Em relação ao tamanho da massa crítica nacional, as taxas de cooperação científica com outros países estão bem aquém das potencialidades. A experiência do programa "Ciência sem Fronteiras" deveria servir de embrião para essa retomada, naturalmente, escoimado de suas fragilidades.

No campo da pesquisa biomédica, um dos principais desafios atuais tem sido a dificuldade de decifrar a complexidade de enfermidades cada vez mais responsáveis por grande parte da carga de doenças em todo o mundo, inclusive entre os brasileiros - as doenças crônicas não transmissíveis. Em paralelo, a política de pesquisa deve apontar para as enfermidades que atingem os segmentos mais vulneráveis da população - as doenças incidentes em populações negligenciadas. Em outra vertente, os caminhos já abertos pelas tecnologias de edição de genes, bem como o avanço no conhecimento dos mecanismos de diferenciação celular oferecem larga estrada para a pesquisa biomédica. Esses desafios são globais e a inserção do país nessa dinâmica globalizada implicará numa adequada seleção de alvos articulados com a nosologia nacional. A relevante contribuição da biomedicina e da pesquisa clínica brasileiras nos surtos de Zika e Chicungunha e na atual pandemia de COVID-19 são bons exemplos dessa adequação. Em todas essas frentes, torna-se cada vez mais imperativa a compreensão crítica da relação entre as dimensões local e global das pesquisas científicas e tecnológicas em saúde, que sinalizam dinâmicas de cooperação, mas também assimetrias e tensões. Trata-se, assim, de proble- 
matizar a própria ideia de saúde global, em seus contornos históricos e também contingentes, e, dessa forma, refletir sobre os desafios a serem enfrentados e o lugar que o país almeja assumir nesse cenário.

$\mathrm{Na}$ fronteira entre a pesquisa biomédica e a epidemiologia, vale lembrar uma possível mudança de abordagem no terreno dos diagnósticos. Ao invés de diagnósticos individuais, buscando algo já conhecido e para o qual já há uma enfermidade reconhecida, cresce de importância o que se denomina de epidemiologia metagenômica, baseada em sequenciamento maciço de amostras clínicas para descobrir os patógenos presentes - já conhecidos ou não.

No terreno da epidemiologia, um grande desafio nos tempos à frente parece ser a utilização na pesquisa de informações contidas em prontuários e outras fontes rotineiras de cuidado à saúde ou ligadas a outras políticas sociais como fonte de dados, objeto de recente regulamentação legal no país. O desafio está no aperfeiçoamento de tecnologias capazes de garantir a qualidade das informações dessas bases de dados aos requisitos de investigação científica. E também, no controle ético-legal capaz de beneficiar a ciência sem colocar em risco os direitos individuais da cidadania. Em outra clave, entende-se que a epidemiologia brasileira vem mudando de patamar com a disseminação de grandes estudos de coorte, desde as pioneiras coortes de nascimentos de Ribeirão Preto-SP, de Pelotas-RS e do estudo ELSA/Brasil, patrocinados pelo Ministério da Saúde e agências de fomento.

Uma das principais marcas das ciências humanas e sociais neste século tem sido uma avassaladora incorporação de dimensões sociais outrora menos valorizadas em seu repertório. Essas dimensões, tais como gênero, etnia, faixa etária e outras eventuais dimensões identitárias cada vez mais se articulam com outras mais assentadas para uma melhor compreensão do fenômeno social como por exemplo, classe social e religião. Para os estudiosos da determinação social da saúde e da doença, essas aquisições são essenciais e sua presença cresce no repertório de pesquisa social em saúde. Outra frente importante no que diz respeito à contribuição das ciências humanas e sociais têm sido as análises, desenvolvidas nas últimas décadas, sobre a ciência como atividade social, um empreendimento coletivo que se viabiliza, em contextos históricos determinados, mediante repertórios, protocolos, valores, espaços e práticas compartilhados, que envolve atores do mundo científico e também atores de outras esferas da vida social, como a política e a economia. Num cenário marcado por negacionismos e questionamentos à expertise e à credibilidade da ciência, as reflexões promovidas no campo dos chamados estudos sociais da ciência e da tecnologia sobre os processos históricos e sociais de produção dos consensos científicos ganham ainda mais relevância para os debates e políticas que visem fortalecer as relações entre ciência e democracia.

Menção especial deve ser dada à pesquisa clínica. $\mathrm{O}$ acelerado crescimento de projetos de pesquisa com seres humanos faz que a vigilância sobre os riscos enfrentados pelos participantes deva ser objeto de atenção igualmente crescente. As estruturas para a revisão ética montadas sob a égide do Conselho Nacional de Saúde - o sistema CEP/CONEP - vêm cumprindo um importante papel na mitigação desses riscos e a garantia de sua preservação e independência são itens importantes da agenda da pesquisa em saúde. A busca permanente da padrões sólidos de integridade científica é uma dimensão central na política de CT\&I/S. Possui uma incidência importante na pesquisa clínica, habitualmente próxima de interesses comerciais e é objeto central no trabalho dos bioeticistas.

A sucessão de episódios epidêmicos que vêm ocorrendo no Brasil e no mundo alerta para esse muito provável emaranhamento de variáveis biomédicas, clínicas, epidemiológicas, sociais e ambientais na determinação e na dinâmica dos mesmos, denominada de sindemia ${ }^{3}$. A pandemia de COVID-19 é o episódio mais grave, mas nem de longe o único ou o último. No Brasil, observam-se surtos recentes de febre amarela silvestre invadindo ambientes urbanos, bem como um leque de patologias associadas ao Aedes Aegypti. $\mathrm{O}$ crescimento do risco de novos eventos catastróficos decorrentes de enfermidades transmissíveis coloca-se como um grande desafio para formuladores de política, gestores e pesquisadores no campo da saúde que, portanto, necessitarão de aportes científicos e tecnológicos. No âmbito da infraestrutura de pesquisa necessária para o enfrentamento desses desafios, será prioritária a montagem de laboratórios de segurança biológica de nível 3, ainda inexistentes no país. Este é um exemplo importante de investimento que está atualmente limitado pela política de austeridade focada na redução dos gastos públicos, cujo marco principal é a Emenda Constitucional 95.

Finalmente, em uma agenda de pesquisa não poderá faltar o olhar para a investigação sobre o próprio metabolismo do SUS, sua gestão, polí- 
ticas, fragilidades e sucessos, bem como sobre o desenvolvimento dos componentes não-públicos de serviços de saúde, sujeitos de crises cíclicas e habitualmente propensos a resolvê-las às custas das conquistas do SUS.

\section{Inovação Produtiva em Saúde}

Segundo o Manual de Oslo em sua última edição $(2018)^{4}$, o conceito de inovação diz respeito a bens ou serviços novos ou significativamente melhorados introduzidos no mercado e é neste sentido que o termo "Inovação Produtiva é aqui utilizado".

O princípio básico que orienta as propostas deste subtítulo é que o elemento fundamental para o avanço da inovação produtiva em saúde é o fortalecimento do Complexo Econômico-Industrial da Saúde (CEIS) entendido como desenvolvimento articulado e harmônico dos componentes científico-tecnológico, industrial e de serviços. O fortalecimento do CEIS não poderá ocorrer de forma isolada, na medida em que ele tem o concurso de vários segmentos da indústria de transformação não diretamente ligados à saúde, como o complexo químico, o complexo eletroeletrônico e o complexo metalmecânico. Portanto, o fortalecimento do CEIS encontrará melhores condições de avançar se estiver articulado a uma proposta mais ampla de política industrial.

Uma das políticas relevantes surgidas a partir de 2008 no campo do SUS foi a Política de Desenvolvimento Produtivo (PDP). Sua concepção derivou da necessidade de se buscar sinergia entre o desenvolvimento industrial tecnológico e produtivo local e a ampliação do acesso da população a medicamentos, vacinas e equipamentos, assim como promover uma melhor alocação de recursos na compra desses produtos.

O mecanismo básico posto em prática pela política foi o estímulo à formação de parcerias nas quais uma empresa privada e um laboratório público comprometem-se a entregar em prazo especificado ao MS um produto identificado por este como estratégico. Nesse processo houve sempre o compromisso de preços cadentes ao longo do processo e de transferência de tecnologia da empresa privada ao laboratório público. Em contrapartida, o MS concederia exclusividade de compra do produto por um prazo também determinado (habitualmente cinco anos, podendo chegar a 10). Até o final de 2017, o MS estava comprando cerca de 20 medicamentos e vacinas a partir dessas parcerias. Segundo infor- mações do próprio Ministério da Saúde, entre 2008 e 2016 o desenvolvimento dessa política gerou uma economia de cerca de $\mathrm{R} \$ 4,5$ bilhões na aquisição desses produtos, bem como propiciou, em vários casos, a capacitação tecnológica de empresas farmacêuticas e laboratórios públicos. Análise de 186 compras realizadas entre 2009 e 2014 por meio das PDP mostrou economia de recursos em 37 dos 39 medicamentos avaliados ${ }^{5}$.

Após a importante, embora frustrada, iniciativa da Central de Medicamentos no século passado, a Política de Desenvolvimento Produtivo foi a primeira grande iniciativa no campo da saúde pública relacionada ao Complexo Produtivo da Saúde. Seu fortalecimento é uma tarefa prioritária. Entretanto, a partir de 2017 essa política foi sendo paulatinamente desconstruída chegando no dia de hoje a uma situação de desaparecimento completo.

O mecanismo de capacitação tecnológica utilizado nas parcerias era habitualmente o da transferência da tecnologia de um determinado produto do parceiro privado para o laboratório público. Esse mecanismo vem sendo amplamente utilizado há muitos anos no campo de vacinas, com bastante sucesso. Mas para que ele seja bemsucedido é necessário que os laboratórios públicos sejam adequadamente preparados para serem capazes de absorver as tecnologias envolvidas em cada parceria. Há evidências de que vários laboratórios públicos ainda não detêm essa capacidade.

A Política de Desenvolvimento Produtivo vinha enfatizando parcerias envolvendo tecnologias maduras ou mesmo em fase de declínio de seu ciclo de vida. Isso não é grave, haja vista que a produção local dos produtos que embutem essas tecnologias pode trazer ganhos de preço e capacitação técnica nos laboratórios públicos. Mas é necessário estender as ações da política não apenas à transferência de tecnologias já dominadas, mas, a encomendas de projetos de desenvolvimento local de tecnologias originais.

Para sua gestão, a Política de Desenvolvimento Produtivo criou algumas instâncias importantes. A principal delas foi o Grupo Executivo do Complexo Industrial da Saúde (GECIS), imaginado para reunir os entes governamentais envolvidos na operação da política. O GECIS tinha acoplado a ele um Fórum de Competitividade que reunia os parceiros públicos e privados e suas entidades representativas. Além dele, a política criou também instâncias de seleção, acompanhamento e de recurso às decisões já tomadas.

Entretanto, o próprio modelo institucional que deu corpo à Política de Desenvolvimento 
Produtivo foi desmantelado. O GECIS foi extinto em dezembro de 2017 no governo Temer e em 2019 o governo Bolsonaro extinguiu o Departamento responsável pela gestão dessa política (Departamento do Complexo Industrial e da Inovação em Saúde).

Como ferramenta do SUS, a Política de Desenvolvimento Produtivo necessita de forte articulação com órgãos governamentais cujas missões tenham envolvimento com ela. Os mais importantes são o INPI, a ANVISA, o BNDES e a FINEP. Quanto ao primeiro, é importante que seja conferida prioridade ao exame de patentes envolvendo produtos essenciais candidatos a objetos de parcerias, devendo sempre ser observado o interesse público. Quanto à ANVISA, é necessário que sejam também priorizados o exame e a concessão de registros sanitários a esses produtos. O BNDES é relevante tanto em sua vertente de fomento tecnológico quanto na formulação da política industrial como um todo. A FINEP é relevante pelo seu papel de fomento tecnológico. Naturalmente, as duas últimas instituições precisam ser profundamente restauradas quanto a sua missão e capacidade operacional, para que possam cumprir o papel que já tiveram na política de CT\&I/S.

Uma das características mais importantes do panorama global dos medicamentos é o crescimento dos que são produzidos por rotas biotecnológicas. Nesses não existe a possibilidade de ser aplicado o conceito de "medicamento genérico", como decorrência da complexidade de sua estrutura molecular. Por isso foi criado para os mesmos a categoria de biossimilares, aplicada a produtos lançados no mercado após o encerramento do período de proteção patentária do produto original. Essa questão gerou uma polêmica internacional sobre a possibilidade de um biossimilar ser capaz de substituir o original, haja vista não ser uma cópia perfeita, como acontece no caso de um medicamento genérico. A decisão sobre a intercambialidade entre o similar e o original é uma questão decisiva para a saúde pública, haja vista a crescente importância dos biossimilares no tratamento de doenças crônicas como o câncer e as doenças reumáticas e autoimunes. Tal qual a bem-sucedida política de genéricos, considera-se, aqui, que a intercambialidade deva ser ampliada, naturalmente, assegurando-se os conceitos de segurança e eficácia. No que toca a incorporação pelo SUS, devem ser garantidos ainda seus custo -efetividade e seu custo-utilidade.

Ao lado do papel determinante da indústria, uma política de CT\&I/S na qual o SUS tem um papel central obriga a ressaltar a participação importante da inovação produtiva vinculada aos serviços. Inovações tecnológicas nesse terreno podem provocar grandes avanços no cuidado à saúde da população, como comprovam programas de grande impacto já existentes, como por exemplo as tecnologias envolvidas no PNI e na Estratégia da Saúde da Família. De modo geral, nesses casos, a inovação reside na articulação virtuosa entre tecnologias já existentes, o que de nenhum modo lhes retira relevância e criatividade. Pelo contrário, por vezes essa articulação virtuosa é capaz de produzir inovações radicais, como, por exemplo a criação do dia nacional de imunização contra a poliomielite. No terreno dos serviços, as inovações costumam ser menos de produtos e mais de processos e os pesquisadores no campo do planejamento e das políticas de saúde, bem como no das ciências sociais, têm um papel central.

O principal responsável pelo aumento dos gastos em saúde em todo o mundo é o crescimento dos preços dos medicamentos e muitos países vêm aperfeiçoando os mecanismos de controle para se contrapor a essa tendência. No Brasil, o controle de preços teve início em 1999/2000 com a CPI dos medicamentos seguida pela promulgação da Lei dos Genéricos e pela criação da Câmara de Regulação do Mercado de Medicamentos (CMED) em 2003, que até hoje cumpre essa missão. A eficiência da atuação da CMED pode ser medida pelo exame da evolução dos preços médios dos medicamentos entre 2000 e 2017, que sofreu queda de cerca de 20\%, (dados do IBGE e ANVISA), com um crescimento significativo do acesso à população. Essa política de regulação de preços deve ser mantida, tendo como norte a ampliação do acesso e o uso racional dos medicamentos. Muito embora os estímulos ao desenvolvimento tecnológico e da inovação na indústria farmacêutica devam ser perseguidos, eles devem estar subordinados à missão essencial dos medicamentos e vacinas, que é o de mitigar o sofrimento e salvar vidas. E o preço dos medicamentos é fundamental neste quesito.

\section{Propriedade Intelectual}

As relações entre as políticas de propriedade intelectual e de saúde pública há muito tempo são objeto de tensão e disputa. Nos últimos anos contribuem para elas o sucesso das políticas de genéricos em vários países e o aprofundamento das iniciativas dos EUA e da União Europeia para incluir em seus acordos de livre comércio cláusu- 
las restritivas relativas ao regime de patentes. Entre outros, esses dispositivos ampliam o escopo da concessão de patentes, aumentam os períodos de proteção patentária, interditam o acesso a dados e proíbem ou dificultam a utilização das flexibilidades dos acordos TRIPS voltados à saúde pública.

A despeito de uma posição de liderança na construção das flexibilidades da TRIPS, o Brasil deu à sua política de propriedade intelectual, expressa na Lei no 9.279, de 14 de maio de 1996, uma condução que, entre outros problemas, praticamente excluiu a pauta sanitária de suas preocupações. Em outros termos, reforçou o atendimento aos interesses comerciais e alijou a vertente do interesse público. Isso, em nome de uma suposta "segurança jurídica" que seria essencial para garantir os investimentos das multinacionais farmacêuticas no país.

Uma apreciação justa do papel da proteção da propriedade intelectual mediante patentes no terreno dos produtos industriais para a saúde exige a construção de um modelo que privilegie o interesse público, expresso na ampliação racional do acesso a esses produtos através das políticas de saúde. Pelo lado da produção industrial o que deve ser garantido são estímulos adequados à inovação, capazes de estimular o desenvolvimento de novos e melhores produtos. Pelo lado da razão pública, deve ser garantido que o direito de acesso a esses produtos não seja atropelado por patentes frívolas ou pela extensão de seus períodos de proteção. De resto, esse direito, no Brasil, está inscrito no capítulo da saúde da Constituição Federal e se expressa nos princípios de universalidade e integralidade.

O responsável pela aplicação da lei de propriedade intelectual no Brasil é o Instituto $\mathrm{Na}-$ cional de Propriedade Industrial (INPI). Órgão de Estado, ele tem sido sistematicamente negligenciado, tanto pela ausência de investimentos quanto pela crescente carência quantitativa de um quadro de examinadores de patentes à altura de suas necessidades. Ao invés de resolver adequadamente essa situação, as últimas direções do INPI vêm propondo esquemas de concessão de patentes que, caso sejam implementados, agredirão frontalmente a soberania brasileira, além de provocar uma enxurrada de ações judiciais para dirimir dúvidas sobre patentes concedidas.

Recentemente aconteceram dois fatos importantes no campo da propriedade intelectual no Brasil. A primeira foi a decisão do STF declarando inconstitucional o parágrafo único do artigo 40 da Lei de Propriedade Intelectual de 1996. Aquele dispositivo permitia descontar o tem- po que o INPI leva para examinar uma patente do período de vigência da mesma, que é de 20 anos. Isso vinha produzindo uma extensão do tempo de vigência das patentes, o que retardava o lançamento de genéricos e biossimilares (mais baratos e produzidos localmente) no mercado. A Ação Direta de Inconstitucionalidade estava no Supremo há mais de dez anos e certamente a emergência pandêmica contribuiu para que fosse colocada em pauta.

O segundo fato, também decorrente da pandemia, foi a aprovação de nova lei, simplificando a decretação de licença compulsória no Brasil em situações de emergência sanitária. A lei brasileira de propriedade intelectual foi aprovada em 1996, apenas dois anos depois da harmonização global sobre patentes, realizada em 1994 na inauguração da OMC e que defendia os pontos de vista dos detentores de patentes, países do Hemisfério Norte (10 empresas farmacêuticas detêm cerca de $40 \%$ do mercado mundial de medicamentos - quatro norte-americanas, duas suíças, uma francesa, uma britânica, uma chinesa e uma japonesa). Nossa lei foi muito permissiva com esses interesses, muito embora nela tenha sido incluída a previsão do mecanismo do licenciamento compulsório em situações de emergência, após a aprovação, em 2002, das flexibilidades do TRIPS em saúde pública. Foi esse dispositivo que permitiu a decretação do primeiro e único licenciamento compulsório no Brasil em 2007 - o antirretroviral Efavirenz.

A lei recentemente aprovada no Congresso significa uma brecha positiva na legislação brasileira no que diz respeito à propriedade intelectual. A lei agora aprovada provoca uma rachadura nesse ambiente legal desfavorável à ampliação do acesso a produtos de saúde na medida em que torna mais ágil o processo de licenciamento. É possível que abra caminho a uma mudança de posição do Brasil no campo da propriedade intelectual. A lei aprovada não provocará impactos imediatos no caso das vacinas contra a COVID-19. Isso porque há um caminho complexo entre ler uma patente e transformá-la em um produto. É preciso saber fazer o produto e para isso é necessário que haja indústrias locais capacitadas tecnológica e produtivamente para trilhar este caminho. No caso de vacinas as duas indústrias (Butantã e Fiocruz) que têm essa capacidade já têm acordo de licenciamento voluntário (CoronaVac e AstraZeneca). Mas é uma fresta aberta que, para a política de CT\&I/S poderá mobilizar os pesquisadores, tanto da área de direito sanitário em busca da ampliação da fissura quanto a 
dos economistas da ciência e tecnologia nas proposições de política industrial em saúde.

Uma estratégia que vem sendo posta em prática por países do Hemisfério Norte é a inclusão de restrições ao acesso a medicamentos e produtos de saúde mediante interdições patentárias incluídas em eventuais acordos de livre-comércio assinados por aqueles países. Tal estratégia deve ser fortemente combatida pelo Brasil, cabendo à comunidade de pesquisa a produção de evidências que suportem essa resistência.

\section{Avaliação e Incorporação de Tecnologias}

Ao lado do aumento de preços, e de modo complementar, o lançamento acrítico de novos produtos industriais de saúde no mercado tem chamado atenção em todo o mundo. A linha de defesa dos sistemas nacionais de saúde - universais ou não - para mitigar esse impacto que é financeiro, mas também diz respeito à segurança dos usuários, tem sido o desenvolvimento de mecanismos de avaliação de tais produtos com vistas à sua incorporação ao mercado público. Esses produtos, com as tecnologias neles embutidas, conformam um gigantesco segmento industrial altamente internacionalizado, oligopolizado e intensivo em pesquisa. Seu valor total ultrapassa um trilhão de dólares. Tais características conferem a ele um enorme poder de pressão política sobre os sistemas de saúde tendo, nas últimas décadas, gerado uma situação na qual, em alguns casos, as empresas detentoras de propriedade sobre tecnologias passam a tutelar os sistemas de saúde. No que refere ao SUS, a despesa anual com essas tecnologias alcança hoje (sem contar as despesas extraordinárias do enfrentamento da pandemia de COVID-19) uma cifra acima de R \$ 20 bilhões, sem levar também em conta os gastos de estados e municípios. Esse aumento contrasta com a contenção e mesmo com a redução, em termos reais, do orçamento da saúde.

A 2a Conferência de Ciência, Tecnologia e Inovação em Saúde em 2004 estabeleceu uma estratégia de incorporação de tecnologias no SUS como um instrumento de aprimoramento da capacidade regulatória do Estado. A implantação da estratégia, liderada pelo Ministério da Saúde a partir de 2005, culminou com uma nova política de gestão de tecnologias em saúde, cujo propósito foi o de maximizar os benefícios à saúde garantindo tecnologias efetivas, seguras e em condições de equidade.

A nova estratégia foi implementada mediante dois movimentos. Um, direcionado à integralida- de da atenção e à institucionalização dos processos de regulação no âmbito governamental, com a criação da Comissão Nacional de Incorporação de Tecnologias no SUS (CONITEC), formalizada pela Lei no 12.401/2011. O outro, voltado para uma política de Avaliação de Tecnologias em Saúde (ATS) com o objetivo de conferir racionalidade ao processo de incorporação tecnológica. Para isso foi criada, em 2008, a Rede Brasileira Avaliação de Tecnologias em Saúde (REBRATS), envolvendo cooperação do governo com universidades, institutos de ensino e pesquisa, hospitais de ensino e órgãos gestores estaduais e municipais. Sua missão tem sido a de formar massa crítica e disseminar no país a prática de ATS.

O modelo adotado pela CONITEC estabeleceu prazos para decisão, critérios, fluxos e procedimentos padronizados, ampliação da participação de gestores estaduais, municipais, conselhos de saúde, profissionais médicos e consulta pública à sociedade. Todavia, o ecossistema da gestão de tecnologias para o SUS continua incompleto e enviesado. Os pedidos de incorporação acontecem desalinhados em relação às prioridades da política pública de saúde. Há pouca participação de usuários, pacientes e gestores nos processos decisórios. A legitimidade e a tempestividade das recomendações e decisões nem sempre são alcançadas. Os processos decisórios frequentemente não estão explícitos ou fundamentados em estudos de alta qualidade. Percebem-se pressões de setores empresariais no perfil de medicamentos e procedimentos a serem incorporados no SUS para tratamento de doenças crônicas, a maioria de alto custo. Minoritariamente, investe-se em intervenções preventivas ou direcionadas à atenção primaria ou mesmo secundária e em procedimentos para populações em condição de vulnerabilidade.

A REBRATS proporcionou padronização, disseminação de métodos, capacitação de pessoal e aumento das colaborações entre pesquisadores no Brasil. Ações de fomento à pesquisa incrementaram estudos de ATS e análises econômicas promovendo expansão de centros de formadores e de pesquisa. No entanto, a rede e seus membros carecem de um papel ativo em promover a interação do conhecimento para subsidiar as decisões de cobertura, a avaliação de desempenho das tecnologias já incorporadas e a identificação de intervenções novas e emergentes que sejam relevantes para a situação de saúde no Brasil.

Num regime democrático, o poder judiciário é uma instância adequada onde os cidadãos e cidadãs lançam mão para verem atendidas reivindicações, justificadas sempre que a esfera admi- 
nistrativa falha em suas obrigações. Entretanto, a partir de 2005, teve início no Brasil uma epidemia de ações judiciais com o objetivo de obrigar o SUS a fornecer produtos e serviços de saúde, em particular medicamentos de alto custo, não incorporados em seus procedimentos. Os processos judiciais impetrados contra gestores nos três níveis do SUS e a normatização legislativa ou administrativa voltada para os cuidados de doenças específicas continuam impondo uma alocação injusta de recursos, muitas vezes provocando desigualdades distributivas e de acesso.

Para tentar resolver o problema da judicialização, foi sancionada em 2011 a Lei no 12.401 cujo objetivo foi regulamentar a integralidade no SUS. Infelizmente, após decisões pouco resolutivas do Supremo Tribunal Federal, essa Lei passou a ser ignorada pelos magistrados, sustentando a epidemia de demandas judiciais. Apesar de alguns avanços decorrentes de ações do Conselho Nacional de Justiça (CNJ) destinadas a orientar os juízes, a questão está longe de ser resolvida. No entanto, deve ser ressaltada a importância de tais medidas do CNJ serem tomadas em total sintonia com a atuação da CONITEC. No âmbito do SUS, este deve ser o "padrão ouro" das evidências científicas com vistas à incorporação. O aperfeiçoamento da ação da CONITEC e da REBRATS e o respeito aos termos da Lei no ${ }^{\circ} 12.401 / 2011$ são requisitos essenciais para a mitigação da epidemia de demandas judiciais, mantendo-se abertas as portas da justiça para as demandas que resultem efetivamente de falhas do SUS.

A despeito dos avanços que resultam do trabalho da CONITEC, o gestor da política pública de saúde deve exercer um papel ativo no estabelecimento de suas prioridades. A CONITEC foi concebida para estar a serviço do SUS e não dos interesses comerciais da indústria. E cabe também à comunidade de pesquisa gerar evidências capazes de contribuir para que correções de rota possam ser implementadas.

\section{O que a pandemia nos ensina e suas repercussões na política de CT\&I/S}

A pandemia de COVID-19 tem colocado desafios no campo da CT\&I/S que não se extinguirão com o seu fim. Processo ainda em curso, não é possível neste momento identificar um conjunto definitivo desses desafios. Portanto, sem a intenção de esgotá-los, seguem alguns pontos importantes que vêm sendo aprendidos.

A pandemia deixou claro o que já se insinuava há umas poucas décadas. Em meados do sé- culo passado, principalmente com o advento dos antibióticos, houve a ilusão de que as doenças transmissíveis seriam um problema já equacionado e que as doenças crônicas não transmissíveis se tornavam o novo desafio. Certamente, essas últimas respondem hoje pela maior parte da carga global de doenças, mas a epidemia de HIV/ Aids (e a tuberculose multirresistente que ela exacerbou), as doenças transmitidas pelo Aedes (Dengue, Zika e Chicungunha e Febre Amarela urbana), os surtos de Ebola, de SARS, de MERS e de Influenza H1N1 já indicavam que algo estava mudando. A pandemia deixou isso claro e estabelecido.

Inicialmente referida aos países do Hemisfério Norte, os epidemiologistas denominaram a emergência das doenças crônicas não transmissíveis (DCNT) como um fenômeno de "inversão nosológica"; mas a COVID-19 mostrou de modo inquestionável que se trata bem mais de uma "adição nosológica". As doenças transmissíveis vieram para ficar, não apenas entre os países pobres do mundo, como era de costume, mas em todo o planeta. Tudo indica que esse novo panorama está vinculado às consequências dos impactos produzidos na atual etapa do Antropoceno. Este teria se iniciado com o século XIX, mas é na fase atual dos séculos XX/XXI que está sendo produzido um grande desastre socioambiental. Em particular, os últimos episódios epidêmicos e pandêmicos vêm sendo expressões de spillovers, ou seja, salto de patógenos de animais para humanos, que são e serão ameaças constantes. É preciso, portanto, ficar claro que doenças transmissíveis não são inimigos em retirada, que podemos vencer e nos despreocuparmos. Na realidade são ameaças perenes e multifacetadas, para cujo enfrentamento será necessária vigilância permanente e intensa. Se isso é verdade, medidas para mitigar a volta das doenças transmissíveis como problema global estão vinculadas à introdução de modelos mais justos e sustentáveis de desenvolvimento econômico e social. A construção desses modelos é tributária, em grande parte, de abordagem científica e tecnológica e a política de CT\&I deve se debruçar sobre ela. Mas, essa revisão do papel das doenças transmissíveis não elide o fato de que as DCNT sejam atualmente responsáveis pela maior parte da carga de doença em todo o mundo, inclusive nos países em desenvolvimento. E aqui também a pandemia trouxe aprendizado, a começar pelo aumento das dificuldades no cuidado com as DCNT, em função do colapso de alguns componentes dos sistemas de saúde estressados pelo combate à COVID-19. 
Um segundo aprendizado que veio da COVID-19 é o reforço da ideia de integração de saberes e da complexidade. A doença causada pelo SARS-CoV-2 expôs de modo claro essa ideia. Sua biologia é diferente da de seus primos causadores de SARS e MERS. Em sua fisiopatologia, o que se pensava ser uma enfermidade respiratória revelou-se uma condição sistêmica. No plano da abordagem clínica, houve surpresas com uma evolução heterodoxa, na qual sintomas prodrômicos transformavam-se rapidamente em doença grave, sem que o bom estado geral dos pacientes fosse condizente com a gravidade de sua real função respiratória. No terreno epidemiológico, o acompanhamento do estado imunitário da população também surpreendeu pela pouca presença de portadores de anticorpos quando a situação é comparada com a experiência de outras epidemias virais.

No planejamento dos serviços de saúde, a velocidade do adoecimento e a gravidade de parte dos pacientes revelaram-se maior e mais intensa do que a organização de rotina estava preparada para suportar. No plano social, explicitou-se com clareza inusual a desigualdade, expressa em marcadores de gênero, etnia, raça e classe, como dimensão estrutural da sociedade brasileira, desigualdade essa que produziu o agravamento da pandemia e ao mesmo tempo foi agravada por ela, impondo custos que certamente terão efeitos muito além da temporalidade da emergência. Volta-se aqui à ideia de que a pandemia de COVID-19 é uma sindemia, conforme mencionado anteriormente neste texto.

Cabe mencionar ainda o impacto da COVID-19 na percepção pública da ciência. Notamse, nesse sentido, efeitos contraditórios: por um lado, se intensificam as expectativas da sociedade quanto aos benefícios da ciência e da tecnologia. Por outro lado, os usos políticos das incertezas (considerando-se a provisoriedade dos consensos e o modo pelo qual são acessados pelo grande público) amplificam dúvidas e inseguranças e, dessa forma, prejudicam a implementação das próprias medidas para o enfrentamento da pandemia. Além dessas dimensões, os serviços, a vida em sociedade no mundo do trabalho, do afeto, do lazer, etc., foram também inesperadamente desorganizados, assim como a economia dos países, alguns já bastante fragilizados antes mesmo da pandemia. Essas expressões de complexidade trazidas pela pandemia também vieram para ficar. Cada vez mais, a abordagem unidimensional de fenômenos sanitários dessa magnitude tende à obsolescência.
Um terceiro aprendizado, este brasileiro, foi o reconhecimento do SUS como ferramenta essencial no campo das políticas públicas por parte expressiva da população brasileira. Convém que esse tardio reconhecimento não arrefeça após o fim da pandemia. Isso significa dar ao SUS apoio político e financeiro adequado ao cumprimento de sua missão.

Em paralelo ao reconhecimento do SUS, a pandemia trouxe à tona o reconhecimento das fragilidades do Complexo Econômico-Industrial da Saúde (CEIS) do país. A corrida global por materiais, equipamentos e vacinas contra a COVID-19 demonstrou que a subordinação do CEIS a uma harmoniosa complementaridade das cadeias produtivas globais não funcionou durante a pandemia e, provavelmente, não voltará tão cedo a funcionar, em face da guerra comercial travada atualmente entre os poderes globais. $\mathrm{O}$ exemplo mais eloquente veio da corrida geopolítica das vacinas (Estados Unidos, China, Rússia e Reino Unido) quando ficou absolutamente claro que o exercício de poder político sobrepujou quaisquer considerações humanitárias e também sanitárias, a despeito da OMS ter criado um mecanismo (o COVAX) para garantir uma distribuição minimamente equânime de vacinas.

No caso brasileiro, país classificado como de renda média alta, detentor de capacidade industrial bastante razoável, as cadeias produtivas globais não funcionaram para máscaras, seringas, respiradores, e principalmente, para componentes essenciais de fabricação de vacinas por Butantã e Fiocruz. É verdade que o fracasso brasileiro dependeu também do fracasso político e diplomático a que o governo federal submeteu o país. Entretanto, o que fica como lição é o grau de autossuficiência do Brasil em vários segmentos industriais, e em particular, os de medicamentos e vacinas terá que aumentar. Para tanto, há que se buscar o reforço financeiro e político das atividades de pesquisa de bancada e, principalmente, a articulação entre esta e os agentes de inovação produtiva. Uma medida fundamental para que haja recursos para tanto passa pela revogação imediata da Emenda Constitucional 95 e pelo enfrentamento das iniciativas sucessivas de se derrubar os pisos orçamentários da saúde e da educação.

Por fim, a pandemia demonstrou com grande intensidade e clareza a importância do engajamento da sociedade como um todo no mundo da ciência, da tecnologia e da inovação. Em particular em países como o Brasil, onde houve uma condução desastrosa no enfrentamento da 
COVID-19. Mas, em todo o mundo a dimensão societária da pandemia vem exigindo um gigantesco fluxo de informações técnicas oriundas de setores especializados, destinado à população em geral. Esse fluxo tem servido tanto para disseminar orientações de boa qualidade técnica quanto para mitigar os efeitos de orientações negacionistas e anticientíficas oriundas de diversas fontes, no caso brasileiro principalmente do governo federal. Uma das expressões mais notáveis desses

\section{Colaboradores}

R Guimarães idealizou e preparou uma versão preliminar do texto. Todos os demais autores participaram igualmente com contribuições substantivas nas seções correspondentes às suas áreas específicas de interesse e competência. canais de informação amplificados pela pandemia foi a presença de profissionais de saúde, epidemiologistas, pesquisadores da área biomédica, gestores no campo da saúde e cientistas sociais em veículos da grande mídia. O desafio que entendemos deva sobreviver ao tempo da pandemia é o de manter abertos esses canais, tornando a divulgação científica e tecnológica um instrumento central e fundamental da política pública de saúde.

\section{Referências}

1. Guimarães R, Noronha J, Elias FTS, Gadelha CAG, Carvalheiro JR, Ribeiro A. Política de Ciência, Tecnologia e Inovação em Saúde. Cien Saude Colet 2019; 24(3):881-886.

2. De Negri F. Políticas Públicas para Ciência e Tecnologia no Brasil: Cenário e Evolução Recente. Brasília: Ipea; 2021.

3. Singer M, Clais S. Syndemics and Public Health: Reconceptualizing Disease in Bio-Social Context. Med Anthropol Q 2003; 17(4):423-441.

4. Organisation for Economic Co-operation and Development (OECD/Eurostat). Oslo Manual 2018. Guidelines For Collecting, Reporting and Using Data on Innovation. $4^{\mathrm{a}}$ ed. Paris/Eurostat, Luxembourg: OECD Publishing; 2018.

5. Albareda A, Torres RL. Avaliação da economicidade e da vantajosidade nas Parcerias para o Desenvolvimento Produtivo. Cad Saude Publica 2021; 37(3):e00070320.

Artigo apresentado em 30/09/2021 Aprovado em 05/10/2021

Versão final apresentada em 07/10/2021

Editores-chefes: Romeu Gomes, Antônio Augusto Moura da Silva 